\title{
New Aspects of Central Nervous System Adaptation to Prenatal Hypoxia
}

D01. $10.17691 / \mathrm{stm} 2018.10 .4 .07$

Received August 8, 2018

M.D. Urazov, Junior Researcher, Laboratory for Neuroprotection Methods Development, Center for Translational Technologies ${ }^{1}$; PhD Student, Department of Neurotechnologies, Institute of Biology and Biomedicine";

T.A. Astrakhanova, Junior Researcher, Laboratory for Neuroprotection Methods Development, Center for Translational Technologies ${ }^{1}$; PhD Student, Department of Neurotechnologies, Institute of Biology and Biomedicine';

A.V. Usenko, Laboratory Assistant, Laboratory for Neuroprotection Methods Development, Center for Translational Technologies ${ }^{1}$; Master, Department of Neurotechnologies, Institute of Biology and Biomedicine';

T.A. Mishchenko, PhD, Senior Researcher, Laboratory for Neuroprotection Methods Development, Center for Translational Technologies ${ }^{1}$; Senior Researcher, Molecular and Cell Technologies Department, Central Scientific Research Laboratory²;

N.A. Schelchkova, PhD, Associate Professor, Department of Neurotechnologies, Institute of Biology and Biomedicine ${ }^{1}$; Head of Molecular and Cell Technologies Department, Central Scientific Research Laboratory;

G.A. Kravchenko, PhD, Associate Professor, Department of Molecular Biology and Immunology, Institute of Biology and Biomedicine ${ }^{1}$,

M.V. Vedunova, DSc, Leading Researcher, Institute of Biology and Biomedicine ${ }^{1 ;}$

Director of Institute of Biology and Biomedicine";

E.V. Mitroshina, PhD, Associate Professor, Department of Neurotechnologies,

Institute of Biology and Biomedicine ${ }^{1}$; Senior Researcher, Laboratory for Neuroprotection Methods Development,

Center for Translational Technologies'; Senior Researcher, Molecular and Cell Technologies Department,

Central Scientific Research Laboratory ${ }^{2}$

${ }^{1}$ National Research Lobachevsky State University of Nizhny Novgorod, 23 Prospekt Gagarina, Nizhny Novgorod, 603950, Russia;

2Privolzhsky Research Medical University, 10/1 Minin and Pozharsky Square, Nizhny Novgorod, 603005, Russia

The aim of the investigation was to study the effect of chronic and acute prenatal hypoxia on the parameters of CNS functional activity and to assess the role of mitochondria in the protection of the CNS against experimental hypoxic influence in vivo.

Materials and Methods. The experiments in vivo were performed on C57BL/6 mice. In order to model chronic prenatal hypoxia, pregnant female mice were placed daily into a hypobaric chamber beginning with the fourteenth day of gestation up to delivery. 280-300 mm Hg pressure corresponding to the altitude of $8000 \mathrm{~m}$ above sea level was maintained in the chamber for $2 \mathrm{~h}$. Acute prenatal hypoxia was modeled on the eighteenth day of gestation. Pregnant females were placed for 4-5 min (till the first agonal breath) in the hypobaric chamber under 220-240 mm Hg pressure corresponding to the altitude of 10,000 $\mathrm{m}$ above sea level.

Oxygen consumption rate by mice brain mitochondria was assessed on the first day of the post-natal period using a high-resolution Oxygraph-2k respirometer (Oroboros Instruments, Austria). To determine a general state of the CNS in the remote post-hypoxic period, a neurological status of the 4-week-old animals was evaluated according to the neurological deficit scale for small laboratory animals and Garcia's scale. Mnestic and cognitive abilities were also tested in Morris water maze.

Results. Protocols of acute and chronic prenatal hypoxia modeling for mice have been designed. Acute hypoxic damage has been shown to result in the significant decrease of the basal oxygen consumption rate and intensity of oxidative phosphorylation by the brain

Corresponding author: Elena V. Mitroshina, e-mail: helenmitroshina@gmail.com 
mitochondria of the newborn mice, and in the activation of the respiratory complex II. After chronic prenatal hypoxia, the basal oxygen consumption rate and oxidative phosphorylation intensity significantly increased relative to the intact group.

Conclusion. The designed protocols of experimental prenatal hypoxia modeling allowed us to reveal a specific pattern of mitochondrial apparatus adaptation to various types of hypoxic damage. Chronic hypoxia leads to adaptation of the mitochondrial apparatus characterized by intensification of oxidative phosphorylation.

Key words: prenatal hypoxia; oxidative phosphorylation; mitochondria; CNS.

\section{Introduction}

Prenatal hypoxia is a pathological condition characterized by a decreased oxygen content in the tissues and is currently regarded as one of the key factors determining pathogenesis of a wide spectrum of fetus diseases. Severe CNS hypoxic injuries in the prenatal period may cause damages of the developing fetus and give rise to encephalopathy, infantile cerebral paralysis, asphyxia, hydrocephalia, secondary microcephaly, and be also one of the main causes of a gross delay of psychoemotional development, convulsive symptoms and infant mortality [1].

According to statistics, $65 \%$ of CNS damages in newborns are caused by hypoxic-ischemic impairments and only $15 \%$ of cases fall on different post-natal and genetic factors [2]. CNS damages result in child disability in $20.6 \%$ of cases, perinatal factors being the main reason in $70-80 \%$ [3].

Consequences of prenatal hypoxia do not always correlate with the degree of its severity. The periods of ontogenesis at which impairments of oxygen supply occurred are of great importance. Several critical periods have been distinguished during prenatal and early postnatal ontogenesis when an organism (especially the brain) becomes particularly vulnerable to unfavorable effects and the negative consequences of such impacts are the most significant [4].

Impairments caused by hypoxia during early ontogenesis can lead not only to gross developmental defects (congenital abnormalities - malformations) but to various functional disorders in the activity of cells, organs and systems of the body. The damaging factors that influence at the period of active organogenesis can cause fetus death, increased frequency of chromosome aberrations in the cells of the body tissues, and such malformations as anencephalia, acephalia, anophthalmia, cleft lip, phocomelia, amelia, astomia, etc. may also appear. Emergence of functional disorders is connected with later terms of prenatal ontogenesis $[5,6]$.

In some especially sensitive brain structures, for example, in cerebral cortex, the normal balance of neuromediators (glutamate, dopamine, serotonin, acetylcholine, etc.) and products of their metabolism changes under hypoxic action [7], besides, structural and functional impairments of cell membrane properties take place causing cells to die [8]. Hypoxia is also able to change the transcription activity of genes responsible for programmed cell death [9].
At the same time, many specific aspects of CNS adaptation to hypoxia in the prenatal period, especially compensatory reactions of the neuronal mitochondrial apparatus, remain unexplored. Their study will allow scientists to solve one of the burning problems of the fundamental and practical medicine.

Investigations on animal models play an important role in the process of studying prenatal hypoxia and its adverse effects. However, currently developed experimental models are not accurate enough since they often do not make it possible to achieve pronounced hypoxic injury of the fetus brain and to examine the effect of chronic hypoxic prenatal stress. The overwhelming majority of authors offer different variants of a single hypoxic impact on a pregnant mouse $[5,7,10,11]$. As the adaptation potential in experimental animals is higher than in a human, such approaches do not allow the researchers to achieve marked impairments of the CNS function. It should be also taken into consideration that approximation of the experimental data obtained by modeling the pathology on animals to a human being requires knowledge of the relation of the main behavioral characteristics and critical periods of fetus development in humans and experimental animals. Therefore, the development of an adequate complex model for testing the CNS condition under hypoxic post-natal stress is a vital problem of the experimental medicine.

Moreover, special attention should be paid to the methods for the assessment of cognitive functions and a general condition of the CNS. It is important to take into account the time of exposure, critical terms of the greatest vulnerability of the nerve cells during pregnancy.

Pregnancy of experimental animals and humans is commonly considered to be divided into three periods. The beginning of the third trimester of pregnancy in mice is a stage during which processes of cell proliferation and migration are running actively in the embryo brains. This is also the most important nascent stage for congenital forms of locomotor behavior. Periods of proliferation and migration of neuroblasts, their maturation and differentiation are significant for the adequate development of cognitive processes. Impairment of embryonal development during these periods may be the reason for damaging the mechanisms of long-term and short-term memory [12].

Considering all these data, chronic prenatal hypoxia was modeled daily on animals from the fourteenth day of pregnancy. Acute prenatal hypoxia was performed once on the eighteenth day of gestation when the level of cell 
proliferation in the brain decreases and the processes of their maturation and differentiation accelerate.

The aim of the investigation was to study the effect of chronic and acute prenatal hypoxia on the parameters of CNS functional activity and to assess the role of mitochondria in the protection of the CNS against experimental hypoxic influence in vivo.

\section{Materials and Methods}

The object of the investigation. Experiments in vivo were performed on C57BL/6 mice. The animals were kept in a licensed vivarium of the National Research Lobachevsky State University of Nizhny Novgorod in compliance with the orders No.1179 $\mathrm{MH}$ USSR of 11.10.1983 and No.267 MH RF of 19.06.2003, experiments were conducted in conformity with the Guide for the Care and use of Laboratory Animals (National Research Council, 2011), met the requirements of the European Convention for the Protection of Vertebrate Animals used for Experimental and Other Scientific Purposes (Strasbourg, 2006), and were approved by the Bioethics Committee of the National Research Lobachevsky State University of Nizhny Novgorod.

In order to model chronic prenatal hypoxia, pregnant female mice were placed daily into the hypobaric chamber beginning with the fourteenth day of gestation (E14) to delivery. 280-300 mm Hg pressure corresponding to the altitude of $8000 \mathrm{~m}$ above sea level was maintained in the chamber for $2 \mathrm{~h}$.

Acute prenatal hypoxia was modeled on the eighteenth day of gestation (E18). Pregnant females were placed for 4-5 min till the first agonal breath in the hypobaric chamber under 220-240 $\mathrm{mm} \mathrm{Hg}$ pressure corresponding to the altitude of $10,000 \mathrm{~m}$ above sea level

Neurological status assessment. To determine the general state of the CNS after hypoxic influence, a neurological status was evaluated according to the neurological deficit scale for small laboratory animals and Garcia's scale. Both scales represent a series of simple tests for various cognitive animal capabilities with a scoring system of evaluation. To assess the scale of neurological deficit for small laboratory animals, a test consisting of 10 behavior reactions is performed where each reaction is assigned a score from 0 to 2 points where 2 points mean no reaction. The points obtained are summed up. The results of neurological status are interpreted as follows:

from 10 to 20 points - severe CNS damage;

from 6 to 9 points - moderate CNS damage;

from 1 to 5 points - slight CNS damage.

Garcia's scale uses 6 tests to evaluate the asymmetry of animal movements and reactions in points (from 1 (severe damages) to 3 (no damages)) which then are summed up. Minimal neurological score is equal to 3 points (maximal damages) and maximal one is 18 points (no damages).
To predict possible remote consequences of prenatal hypoxia and their influence on animal metabolism, the mass of newborn mice was evaluated in dynamics.

The processes of spatial learning and memory were tested using Morris water maze [13] according to the modified protocol by Frick et al. [14]. The process of learning in the maze lasted for 5 days and included 5 sessions of 3 trials with a $30 \mathrm{~s}$ inter-trial intervals for searching a platform for each animal. On day 7, the platform was removed from the pool and each animal underwent a single test during $60 \mathrm{~s}$. In addition to recording the delayed coefficient of retention $(\mathrm{dCr})$, i.e. a fraction of time during which an animal was in the zone where the platform had been relative to the total time of being in the Morris water maze, the following parameters were also evaluated:

the character of searching for the target by the animal in the Morris maze (a direct search - the animal swam straight to the place where the platform had been previously located; an active search - the animal made circular and radial searching movements before reaching the target; chaotic search - absence of the apparent strategy of reaching the target);

the path traveled by the animal to reach the target (the distance traveled from the moment of placement in the Morris maze up to finding the place of the previous platform location) [13].

Assessment of mitochondria functional state. Oxygen consumption rate by mitochondria was determined in order to analyze the effect of hypoxia on their functional state. Mitochondria functional activity was assessed in the newborn mice $24 \mathrm{~h}$ after delivery. All manipulations were made on ice. The equipment and isolation media were cooled. Mitochondria were isolated from the brain tissue using differential centrifugation [15, 16]. Protein quantitation in the isolated mitochondria was performed using Bradford method. Oxygen consumption by the isolated mitochondria was registered polarographically in a high-resolution respirometer Oxygraph-2k (Oroboros Instruments, Austria) in $2 \mathrm{ml}$ of incubation media (210 mM mannitol; $70 \mathrm{mM}$ saccharose; $0.1 \mathrm{mM}$ EGTA; $10 \mathrm{mM}$ HEPES; $\mathrm{pH}$ 7.4) at a constant stirring. Oxygen $\left(\mathrm{O}_{2}\right)$ consumption rate was expressed in picomoles (pmole) per $1 \mathrm{~s}$ per $1 \mathrm{mg}$ of mitochondrial protein.

The results obtained are presented as mean \pm standard error of mean $(\mathrm{M} \pm \mathrm{SEM})$. The significance of differences between the experimental groups was determined using Mann-Whitney test in a SigmaPlot 11.0 program (USA). Differences were considered statistically significant at $p \leq 0.01$.

\section{Results}

First, the methodology of chronic prenatal hypoxia modeling was chosen and modified. The main requirement for the protocol was its ability to preserve sufficiently the viability of pregnant mice in chronic 
experiment. Therefore, we tested various elevation heights: 10,500, 9000, and $8000 \mathrm{~m}$. Lifetime at 10,500 m was in the range from 2 to $10 \mathrm{~min}$, at $9000 \mathrm{~m}$ up to $20 \mathrm{~min}$, at 8000 about $120 \mathrm{~min}$. Since the development of the relevant model required the longest possible hypoxic influence, we have chosen the height at which the mice maintained the viability for $2 \mathrm{~h}$.

As active formation of synaptic contacts between neurons begins after formation of the main morphological brain structures during embryogenesis, the fourteenth day of gestation corresponding to the third trimester was selected as an optimal period to start modeling chronic hypoxia. Thus, the protocol of chronic prenatal hypoxia modeling implied the elevation of the pregnant female mice (E14) in the vacuum flow-type chamber to a height of $8000 \mathrm{~m}$ at a speed of $183 \mathrm{~m} / \mathrm{s}$ for $2 \mathrm{~h}$ daily till delivery. This elevation speed was chosen in order to obtain evident hypoxic brain injury. If the elevation speed is slower, immediate adaptation mechanisms of the body may be involved, the situation which should be avoided for the given experimental model.

The eighteenth day of gestation was chosen for modeling acute hypoxia as one of the critical periods of brain formation. This period is characterized by the completion of the neurogenesis process and the beginning of active synaptic contacts formation between mature neurons [17]. Therefore, the mode of elevation to a height of $10,000 \mathrm{~m}$ at a speed of $175-183 \mathrm{~m} / \mathrm{s}$ till the first agonal breath (4-5 min) on the eighteenth day of gestation was chosen for modeling acute prenatal hypoxia.

To assess the functional state of the animals' nervous system at the remote period after chronic prenatal hypoxia, neurological status of the mice was determined. When testing the animals after hypoxia their neurological status score appeared to be completely equal to the score of the intact mice according to both scales, consequently, no significant disorders in the CNS condition had occurred.

During the first 4 weeks of life the dynamics of mice mass had been analyzed (Figure 1). Newborn mice suffered chronic hypoxia had a tendency to the increase of body mass by week 4 relative to the intact animals. The results obtained correlate with the previously published data on the effect of prenatal hypoxia on the disposition to metabolic dysregulation and obesity $[11,18]$.

When animals subjected to chronic prenatal hypoxia reached the age of 1 month their cognitive functions were tested in Morris water maze. The data showed the formation of spatial memory in the experimental mice. The time of finding the platform by the mice from both groups was established to decrease with each subsequent session, the target search became directional. When reproducing the

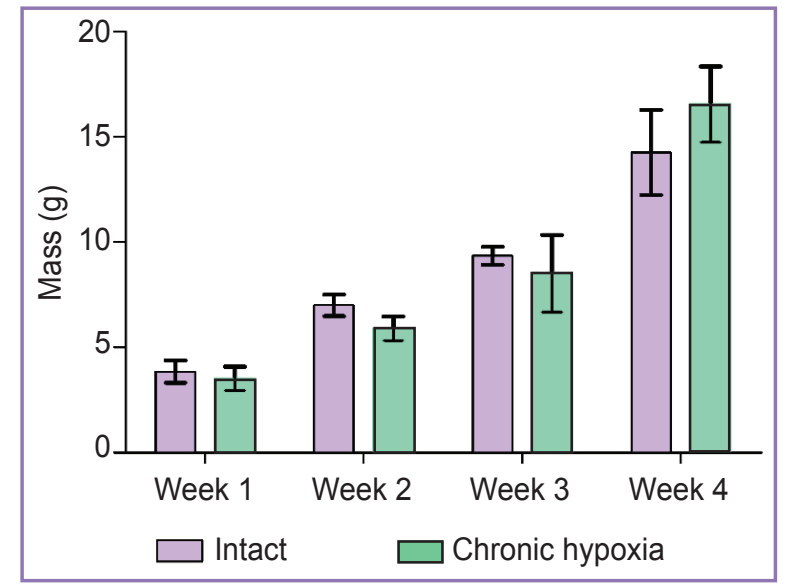

Figure 1. Dynamics of mass in C57BL/6 newborn mice after chronic hypoxia during the first 4 weeks of life

Target search strategy in animals tested in Morris water maze (\%)

\begin{tabular}{lccc}
\hline \multicolumn{1}{c}{ Animals } & $\begin{array}{c}\text { Direct } \\
\text { searching }\end{array}$ & $\begin{array}{c}\text { Active } \\
\text { searching }\end{array}$ & $\begin{array}{c}\text { Chaotic } \\
\text { searching }\end{array}$ \\
\hline Intact & 55 & 27 & 18 \\
Chronic hypoxia & 33 & 45 & 22 \\
\hline
\end{tabular}

skill on day 7 it was noted that more than $50 \%$ of intact animals moved directly to the target (direct search) while only $33 \%$ of animals from "hypoxia" group used direct search and $45 \%$ were actively searching for the target. Thus, the mice suffered chronic hypoxia changed their target search strategy (see the Table).

The delayed coefficient of retention $(\mathrm{dCr})$ and the distance to the target were calculated to assess a long-term memory condition (Figure 2). It was shown that there was a tendency to the decrease of these parameters in the animals subjected to hypoxia though statistically significant differences were not found. The $\mathrm{dCr}$ was $37.5 \pm 7.5 \%$ in the intact mice and $31.8 \pm 5.4 \%$ in the animals after chronic prenatal hypoxia. The track length ranged from 8950 to $10,200 \mathrm{~cm}$.
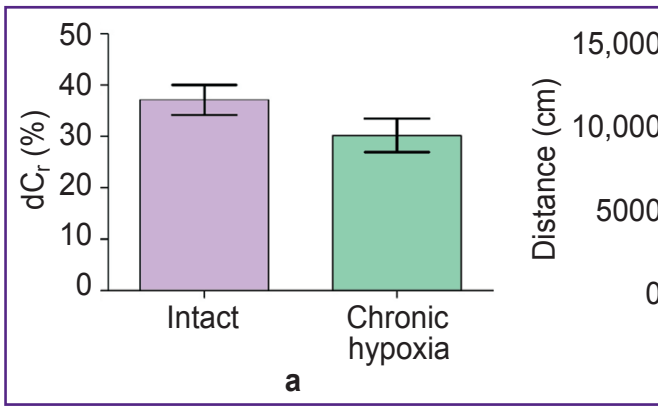

Figure 2. Assessment of the parameters in the mice after testing in Morris water maze:

(a) the delayed coefficient of retention $\left(\mathrm{dC}_{\mathrm{r}}\right)$; (b) the target distance 


\section{EXPERIMENTAL INVESTIGATIONS}

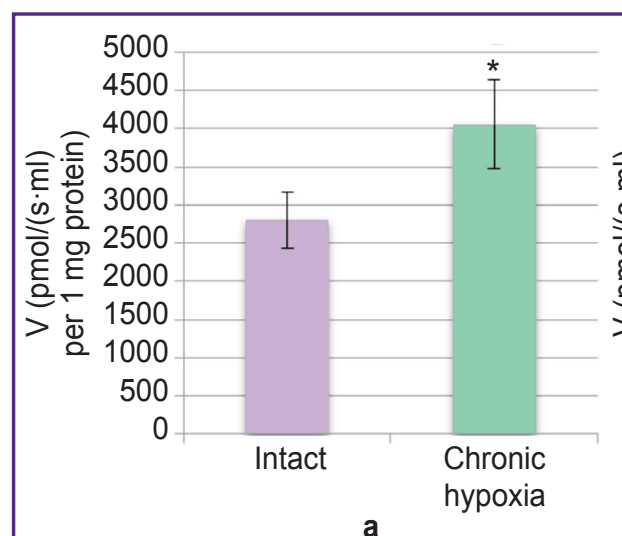

a

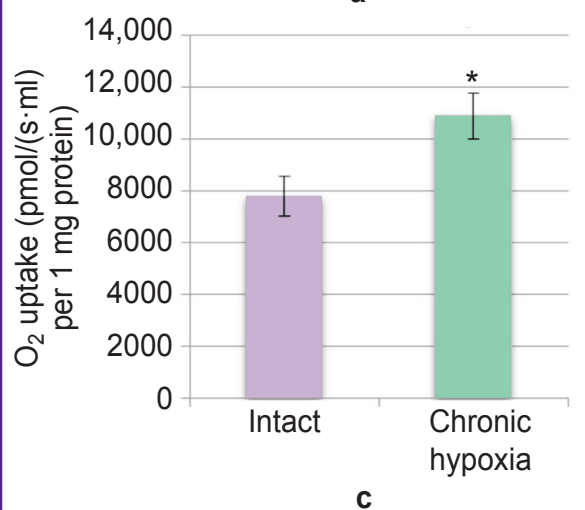

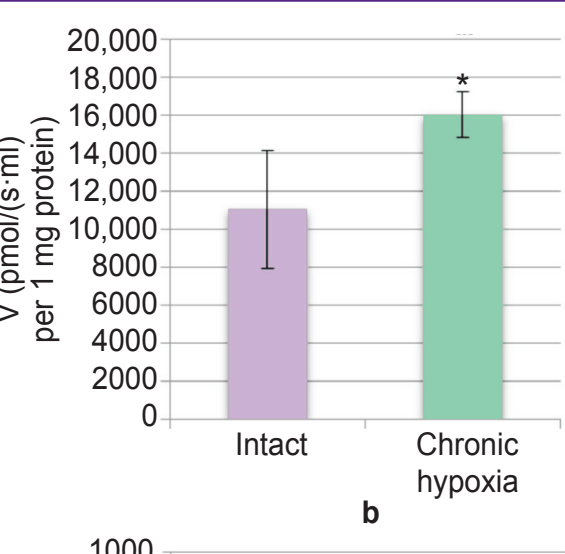

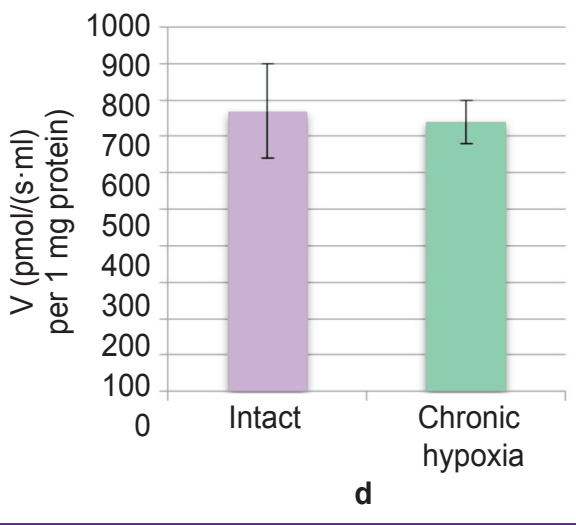

Figure 3. Condition of the mitochondrial respiratory chain in brain cells of the newborn C57BL/6 mice after chronic prenatal hypoxia:

(a) basal oxygen consumption rate by mitochondria in presence of glutamate and malate substrates excess; (b) oxidative phosphorylation of mitochondrial respiratory chain; (c) succinatedependent pathway of substrate oxidation (active work of mitochondrial respiratory chain complex II at succinate oxidation); (d) rotenone-dependent inhibition of mitochondrial respiratory chain complex I; * statistically significant differences from the intact group; $\mathrm{p}<0.01$; Mann-Whitney test
Thus, the designed experimental protocols of prenatal hypoxia modeling passed successful verification because they make it possible to induce cognitive function impairments typical for hypoxic damages in the remote period and changes leading to obesity characteristic for the pups after hypoxia, and thereby to study different aspects of disorders occurring in prenatal hypoxic stress including cellular and molecular levels.

Further, we analyzed the functional state of the mitochondrial respiratory chain in the mice brain cells on day 1 of the post-natal period since in recent years there has been shown a special role of mitochondria in organism adaptation to hypoxic damage [19-21]. The basal oxygen consumption rate at oxidation of glutamate and malate substrates in animals with prenatal chronic hypoxia significantly increased compared to the intact group (2796.4 \pm $366.5 \mathrm{pmol} /(\mathrm{s} \cdot \mathrm{ml})$ per $1 \mathrm{mg}$ protein) by $45 \%$ and made $4053.88 \pm 582.10 \mathrm{pmol} /(\mathrm{s} \cdot \mathrm{ml})$ per $1 \mathrm{mg}$ protein (Figure 3 (a)). The intensity of oxidative phosphorylation in the experimental group $(16,016.38 \pm 1196.90 \mathrm{pmol} /(\mathrm{s} \cdot \mathrm{ml})$ per $1 \mathrm{mg}$ protein) grew by $45 \%$ relative to the intact values $(11,053.3 \pm$ $3112.0 \mathrm{pmol} /(\mathrm{s} \cdot \mathrm{ml})$ per $1 \mathrm{mg}$ protein) (Figure $3(\mathrm{~b})$ ). There was also noted an activity growth of the respiratory chain complex II at which the parameters in the experimental animals $(10,907.80 \pm 884.67 \mathrm{pmol} /(\mathrm{s} \cdot \mathrm{ml})$ per $1 \mathrm{mg}$ protein) were 1.4 times higher than in the intact group $(7796.4 \pm 756.8 \mathrm{pmol} /(\mathrm{s} \cdot \mathrm{ml})$ per $1 \mathrm{mg}$ protein $)$
(Figure 3 (c)). When inhibiting NADH dehydrogenase by rotenone, statistically significant differences between the intact and experimental groups were not obtained (Figure $3(d)$ ).

When the functional state of brain mitochondria in the newborn mice after acute prenatal hypoxia modeling was studied, significant twofold decrease of the basal oxygen consumption rate by mitochondria was registered, the values in the experimental group being 962.16 \pm $57.70 \mathrm{pmol} /(\mathrm{s} \cdot \mathrm{ml})$ per $1 \mathrm{mg}$ protein and in the intact group $2225.6 \pm 80.2 \mathrm{pmol} /(\mathrm{s} \cdot \mathrm{ml})$ per $1 \mathrm{mg}$ protein (Figure 4 (a)). Oxidative phosphorylation activity (Figure 4 (b)) after the acute episode of prenatal hypoxia reduced by 5.1 times relative to the intact values (2514.6 \pm 433.4 and 12,872.8 $\pm 708.7 \mathrm{pmol} /(\mathrm{s} \cdot \mathrm{ml})$ per $1 \mathrm{mg}$ protein, respectively).

Notably, at a period of the marked reduction of the general mitochondria functional activity after modeled acute hypoxia, significant increase of the rate at rotenonedependent inhibition of mitochondrial respiratory chain complex I was observed - the values in the animals with hypoxia were $2339.1 \pm 13.2 \mathrm{pmol} /(\mathrm{s} \cdot \mathrm{ml})$ per $1 \mathrm{mg}$ protein being 6.5 times greater than the intact values $-361.3 \pm 37.0 \mathrm{pmol} /(\mathrm{s} \cdot \mathrm{ml})$ per $1 \mathrm{mg}$ protein (Figure 4 (c)). When mitochondrial respiratory chain complex II was stimulated with succinate, the values in the experimental group were $8860.7 \pm 221.9 \mathrm{pmol} /(\mathrm{s} \cdot \mathrm{ml})$ per $1 \mathrm{mg}$ protein being 1.6 times higher than in the intact mice $-7609.5 \pm 230.1 \mathrm{pmol} /(\mathrm{s} \cdot \mathrm{ml})$ per $1 \mathrm{mg}$ protein (Figure $4(d))$. 
Figure 4. Condition of the mitochondrial respiratory chain in brain cells of the newborn C57BL/6 mice after acute prenatal hypoxia:

(a) basal oxygen consumption rate by mitochondria in presence of glutamate and malate substrates excess; (b) oxidative phosphorylation of mitochondrial respiratory chain; (c) rotenone-dependent inhibition of mitochondrial respiratory chain complex I; (d) succinate-dependent pathway of substrate oxidation (active work of mitochondrial respiratory chain complex II at succinate oxidation); * statistically significant differences from the intact group; $p<0.01$; Mann-Whitney test
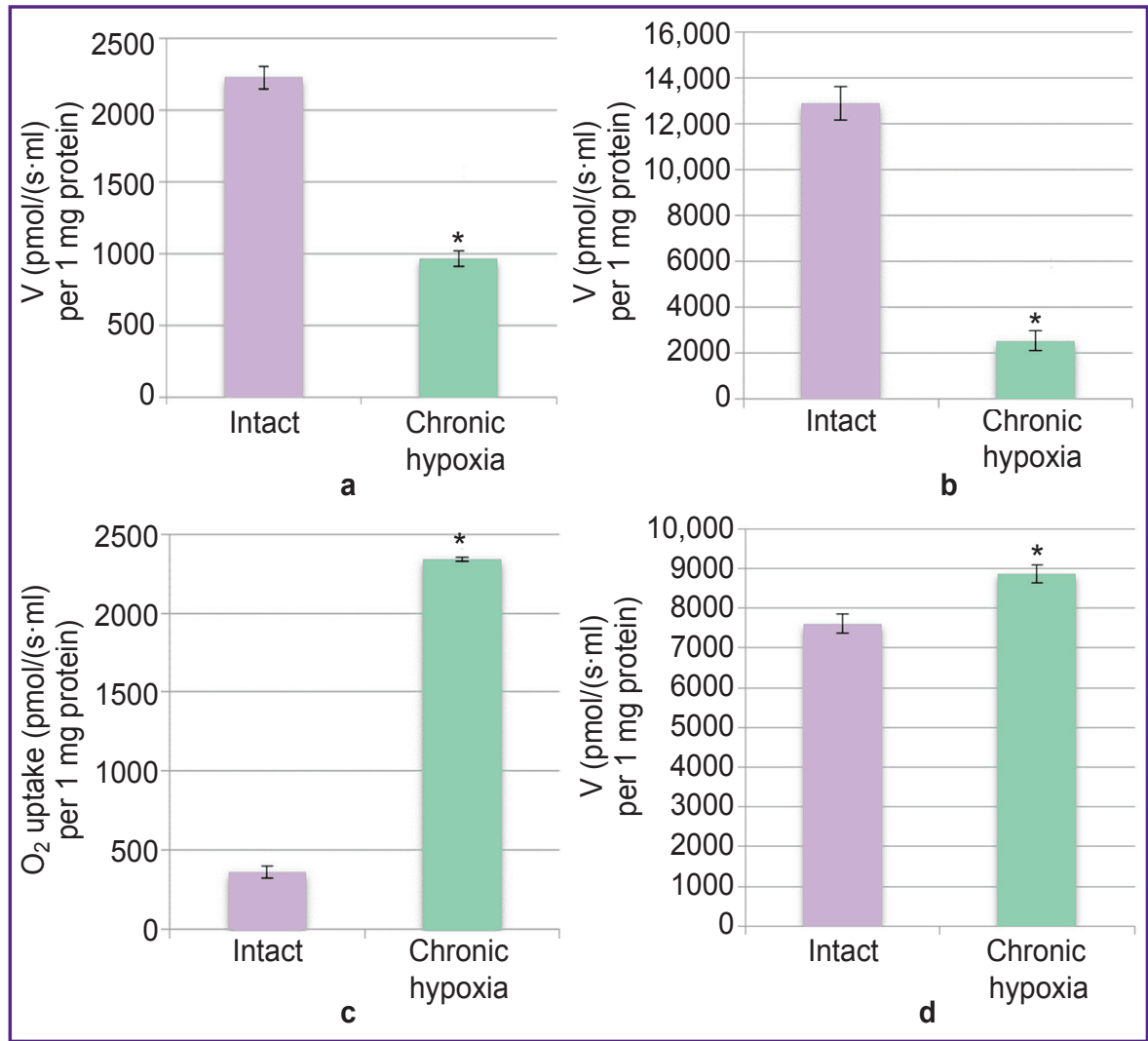

\section{Discussion}

Chronic prenatal hypoxia is the most severe form of hypoxia developing in pregnancy. It results in activation of anaerobic glycolysis. Insufficient oxygen supply to the organism leads to the redistribution of blood circulation with predominant supply to the vital organs. Due to centralization of blood circulation, acidosis takes place accompanied by a sharp growth of lactate level in the blood resulting in greater permeability of the vascular wall and further to the formation of intravascular thrombi. As a result of these and other pathological processes, a severe damage of the brain occurs, the consequences of which may become evident even at the remote post-hypoxic period in the form of various disorders of physiological and cognitive functions, learning processes and memory [10].

Investigations of cognitive functions in animals with chronic prenatal hypoxia at the remote period by the assessment of long-term memory using Morris water maze test showed that over time the target search strategy and a fraction of time being in the zone where the platform had been changed, i.e. the processes of long-term memory formation and reproduction are impaired.

Since no evident disorders of the general CNS state were detected in the course of neurological status assessment, behavioral abnormality in the animals exposed to chronic prenatal hypoxia might not presumably be caused by gross structural damages of the brain. Most likely they may be connected with diverse neurochemical disturbances [22].

Data obtained during mitochondrial respiration investigations are of great interest. Notable are multidirectional changes of the basal oxygen consumption rate by mitochondria and oxidative phosphorylation in acute and chronic hypoxia modeling.

The organism response to hypoxia is known to include different adaptive reactions promoting elimination of functional and metabolic disorders typical for this condition and directed primarily to preservation of mitochondrial functions. Two types of mechanisms are used: (a) immediate (emergency) compensatory mechanisms the aim of which is to prevent the consequences of acute hypoxia and provide rapid restoration at the post-hypoxic period; (b) long-term mechanisms of adaptation to hypoxia which are being formed during a longer period and contribute to the enhancement of nonspecific resistance to oxygen deficit [19].

The processes of intensification of mitochondrial respiration in chronic hypoxia may be supposed to be connected with these long-term mechanisms of adaptation.

Acute hypoxic damage results in activation of the respiratory complex II which is in line with the previously obtained findings during hypoxia modeling in post-natal period [23]. Of special interest are the data on a longterm adaptation of mitochondrial apparatus which may be linked to the synthesis of a large amount of proteins 
of the respiratory chain and nuclear regulation of mitochondrial genome [20].

\section{Conclusion}

Our investigations of brain mitochondria functioning after prenatal hypoxia have shown that acute prenatal hypoxia episode reduces the basal oxygen consumption rate by mitochondria and inhibits oxidative phosphorylation. At the same time, chronic hypoxia results in the adaptation of the mitochondrial apparatus displaying itself in intensification of oxidative phosphorylation. The designed protocols of experimental prenatal hypoxia modeling allowed us to reveal a specific pattern of mitochondrial apparatus adaptation to various types of hypoxic damage.

Study funding. The work was supported by the Russian Science Foundation (project 18-75-10071) with regard to the designing protocols of prenatal hypoxia and by the Government Assignment (projects 17.3335.2017/4.6 and 6.6379.2017/8.9) relating to the study of mitochondrial functional activity.

Conflict of interests. The authors have no conflict of interests to disclose.

\section{References}

1. Ferriero D.M. Neonatal brain injury. N Engl J Med 2004; 351(19): 1985-1995.

2. Semina V.I., Stepanova Y.A. Perinatal hypoxia: pathogenetic aspects and approaches to diagnostics (review of literature). Part I. Meditsinskaya vizualizatsiya 2015; 2: 95-105.

3. Kozlova E.M. Osobennosti pozdnego neonatal'nogo perioda u novorozhdennykh, perenesshikh tyazheluyu perinatal'nuyu gipoksiyu. Avtoref. dis. ... kand. med. nauk [Features of the late neonatal period in newborns suffered severe perinatal hypoxia. PhD Thesis]. Nizhny Novgorod; 2009.

4. Kassil' V.G., Otellin V.A., Khozhai L.I., Kostkin V.B. Critical phases of the brain development. Rossiiskii fiziologicheskii zhurnal im. I.M. Sechenova 2000; 86(11): 1418-1425.

5. Otellin V.A., Khozhai L.I., Vataeva L.A. Effect of hypoxia in early perinatal ontogenesis on behavior and structural characteristics of the rat brain. Zhurnal evolyutsionnoy biokhimii i fiziologii 2012; 48(5): 467-473.

6. Golan $H_{\text {.y }}$ Huleinet $M$. The effect of prenatal hypoxia on brain development: short- and long-term consequences demonstrated in rodent models. Dev Sci 2006; 9(4): 338-349, https://doi.org/10.1111/j.1467-7687.2006.00498.x.

7. Tyul'kova E.1., Semenov D.G., Vataeva L.A., Belyakov A.V. Samoilov M.O. Effect of prenatal hypobaric hypoxia on glutamatergic signal transduction in rat brain. Bull Exp Biol Med 2011; 151(3): 275-277, https://doi.org/10.1007/ s10517-011-1307-y.

8. Lipton P. Ischemic cell death in brain neurons. Physiol Rev 1999; 79(4): 1431-1568, https://doi.org/10.1152/physrev. 1999.79.4.1431.

9. Rybnikova E., Gluschenko T., Tulkova E., Churilova A., Jaroshevich O., Baranova K., Samoilov M. Preconditioning induces prolonged expression of transcription factors $\mathrm{pCREB}$ and NF-kappa B in the neocortex of rats before and following severe hypobaric hypoxia. J Neurochem 2008; 106(3): 14501458, https://doi.org/10.1111/j.1471-4159.2008.05516.x.

10. Bourque S.L., Gragasin F.S., Quon A.L., Mansour Y., Morton J.S., Davidge S.T. Prenatal hypoxia causes long-term alterations in vascular endothelin-1 function in aged male, but not female, offspring. Hypertension 2014; 62(4): 753-758, https://doi.org/10.1161/hypertensionaha.113.01516.

11. Chen L., Zadi Z.H., Zhang J., Scharf S.M., Pae E.K. Intermittent hypoxia in utero damages postnatal growth and cardiovascular function in rats. J Appl Physiol 2018; 124(4): 821-830, https://doi.org/10.1152/japplphysiol.01066.2016.

12. Golan M.H., Mane R., Molczadzki G., Zuckerman M., Kaplan-Louson V., Huleihel M., Perez-Polo J.R. Impaired migration signaling in the hippocampus following prenatal hypoxia. Neuropharmacology 2009; 57(5-6): 511-522, https:// doi.org/10.1016/j.neuropharm.2009.07.028.

13. Morris R. Developments of a water-maze procedure for studying spatial learning in the rat. J Neurosci Methods 1984; 11(1): 47-60, https://doi.org/10.1016/0165-0270(84)90007-4.

14. Frick K.M., Stillner E.T., Berger-Sweeney J. Mice are not little rats. NeuroReport 2000; 11(16): 3461-3465, https:// doi.org/10.1097/00001756-200011090-00013.

15. Egorova M.V., Afanasyev S.A. Isolation of mitochondria from cells and tissues of animals and human: modern methodical approaches. Sibirskiy meditsinskiy zhurnal 2011; 26(1-1): 22-28.

16. Mitroshina E.V., Vedunova M.V., Mironov A.A., Saharnova T.A., Pimashkin A.S., Bobrov M.Y., Khaspeckov L.G., Mukhin I.V. Neuroprotective effect of endacannabinoid $\mathrm{N}$-arachidonoyldopamine in acute hypobaric hypoxia. Nevrologicheskiy vestnik im. Bekhtereva 2012; 44(1): 14-19.

17. Rueda-Clausen C.F., Stanley J.L., Thambiraj D.F., Poudel R., Davidge S.T., Baker P.N. Effect of prenatal hypoxia in transgenic mouse models of preeclampsia and fetal growth restriction. Reprod Sci 2014; 21(4): 492-502, https://doi. org/10.1177/1933719113503401.

18. Khalyfa A., Cortese R., Qiao Z., Ye H., Bao R., Andrade J., Gozal D. Late gestational intermittent hypoxia induces metabolic and epigenetic changes in male adult offspring mice. J Physiol 2017; 595(8): 2551-2568, https://doi. org/10.1113/jp273570.

19. Luk'yanova L.D. Signaling role of mitochondria in adapting to hypoxia. Fiziologichniy zhurnal 2013; 59: 141-154.

20. Wheaton W.W., Chandel N.S. Hypoxia. 2. Hypoxia regulates cellular metabolism. Am J Physiol Cell Physiol 2011; 300(3): 385-393, https://doi.org/10.1152/ajpcell.00485.2010.

21. Kristián T. Metabolic stages, mitochondria and calcium in hypoxic/ischemic brain damage. Cell Calcium 2004; 36(34): 221-0233, https://doi.org/10.1016/j.ceca.2004.02.016.

22. Perrin D., Mamet J., Scarna H., Roux J.C., Bérod A., Dalmaz Y. Long-term prenatal hypoxia alters maturation of brain catecholaminergic systems and motor behavior in rats. Synapse 2004; 54(2): 92-101, https://doi.org/10.1002/syn.20065.

23. Astrakhanova T.A., Urazov M.D., Usenko A.V., Mitroshina E.V., Mishchenko T.A., Schelchkova N.A., Vedunova M.V. BDNF-mediated regulation of the brain mitochondria functional state in hypoxia. Sovremennye tehnologii v medicine 2018; 10(3): 88-94, https://doi.org/10. $17691 / \mathrm{stm} 2018.10 .3 .10$. 